of the image. Selected frames from the best sequences were photographically superimposed by means of a special enlarger with provision for registration of successive frames. For black and white enlargements a 'Minus Blue' filter was used in conjunction with panchromatic film.

W. H. van den Bos contributes the remaining four papers, the first with the title "The Orbit of Rst 33", the second, "The Orbit of $\varphi$ 47", the third, "The Orbit of $\beta 430=\psi$ Sgr.", and the last, "Micrometer Measures of Double Stars". The latter contains 385 measures of 165 pairs, all taken with the $26 \frac{1}{2}$-in. refractor.

\section{Tropical Products Institute}

THE first major removal from the Imperial Institute building in South Kensington, to make way for its demolition, will begin on December 9 . The Colonial Products Laboratory will then be moving to new premises in Gray's Inn Road, London. The name of the organization is also being changed to the Tropical Products Institute in anticipation of its function broadening again to that of assisting and advising territories in tropical and sub-tropical regions which are not necessarily colonies. The building which will accommodate the Tropical Products Institute was erected in 1955 on a bombed site opposite Gray's Inn but was not originally intended for use as laboratories. It has, however, been adapted by the Ministry of Works to provide the Institute with $44,000 \mathrm{sq}$. ft. of good, modern accommodation. Eight self-contained laboratories will be devoted to advisory and research work on the main groups of plant and animal products of the tropics; the staff in these will be responsible for answering inquiries about the renewable resources of the tropics which are referred to the organization from sources at home and overseas. The laboratories together contain a quarter of a mile of benches, which will provide good average working space for the seventy-five laboratory workers that the Institute will have on its staff when it reaches full complement. Some bench space will be devoted to training overseas students and to other visiting workers. The Institute possesses a library of some 150,000 items, which constitutes a unique collection of information on tropical plant and animal products, and of the agriculture and production of the Commonwealth. Much general scientific, tech. nological and trade information is also available. The total staff of the Institute will eventually be about 150 .

\section{Scientific Research in Schools}

A Jornt Committee of the Royal Society and the Science Masters' Association has been formed to consider the problems confronting science masters and mistresses who wish to pursue research and to arrange for advice for specific research projects. The Committee consists of Sir Lindor Brown, biological secretary of the Royal Society (chairman). Dr. F. P. Bowden, Sir Edward Salisbury and Dr. C. G. Williams (representing the Royal Society), and Mr. W. Ashhurst, Mr. R. H. Dyball and Mr. M. C. Nokes (representing the Science Masters' Association). In order to initiate action the Committee has issued a note to teachers of science in schools and has also circularized the head masters and head mistresses of a number of schools in the United Kingdom; and eleven schools had submitted details of research projects and asked advice within a very short time after announcement. The Committee hopes to be assisted in its work by Fellows of the Royal Society and others at universities who may be willing to discuss projects with those who wish to carry out research. This kind of contact between university departments which are intimately concerned with research work and school masters and mistresses who so often feel isolated from the academic world would, in the Committee's opinion, be valuable. It is appreciated that in many schools there are neither facilities, nor has the science staff the opportunity or time, for carrying out any research ; but the Committee thinks that wherever possible encouragement should be given when there is a desire by a science master or mistress to do research, as it is believed that they will themselves benefit in a number of ways and, in consequence, their teaching and their pupils will be better served.

\section{Flow Coefficients}

Drmensional theory permeates the whole field of aerodynamics. It is surprising, therefore, that it has not been systematically applied to the familiar method of metering the flow through a duct by measuring the pressure difference created by a constriction. The usual method of deducing the flow rate involves the application of an artificial correction factor (the so-called discharge coefficient) to the expression derived from an inadequate theoretical model of the flow. In a recent paper in the Journal of Electronics and Control (3, No. 4, 409; 1957), T. H. Redding, of the British Scientific Instrument Research Association, points out that this approach is unsatisfying æesthetically and can lead to serious misconceptions regarding the true significance of such a 'correction factor'. Instead, he applies dimensional analysis, at some length, and arrives at a more soundly based non-dimensional flow coefficient which is a function of the appropriate non-dimensional parameters that characterize the system. Whether or not hydraulic engineers take Mr. Redding's remarks to heart in this particular case, his paper demonstrates the unsatisfactory nature of the 'correction coefficient' philosophy, par. ticularly where the teaching of students is concerned, and provides $a_{0}$ convincing instance of the great power of the methods of dimensional analysis.

\section{The Fossil Pigs of Florisbad}

A RECENT publication of the National Museum at Bloemfontein (Researches of the National Museum, Bloemfontein, 1, Pt. 10, 239 ; 1957) includes a paper by Mr. R. F. Ewer on the fossil suid material recovered from the Florisbad deposit. A re-s ssessment of the status of Phacochoerus venteri and of Phacochoerus helme $i$ is made, and it is concluded that $P$. venter $i$ is not a valid species but is synonymous with $P$. aethiopicus. Also, that although $P$. helmei shows some characteristics which differentiate it from the living $P$. africanus, it is to be regarded as a local subspecies of restricted range, rather than as a distinct species. It therefore becomes Phacochoerus africanus helmei. The fauna suggests that the Florisbad deposits are of Upper Pleistocene age.

\section{Applied Morphogenesis}

IN a study of growth and morphogenesis in Canadian forest spocies, G. H. Duff and N. J. Nolan have made observations on specific increments and their relation to the quantity and activity of growth in Pinus resinosa (Canadian J. Bot., 35, 527; 1957). 